\title{
PH CARE COVID survey: an international patient survey on the care for pulmonary hypertension patients during the early phase of the COVID-19 pandemic
}

Laurent Godinas ${ }^{1,2^{*}} \mathbb{0}$, Keerthana Iyer ${ }^{3,4,5}$, Gergely Meszaros ${ }^{6}$, Rozenn Quarck ${ }^{1,2}$, Pilar Escribano-Subias ${ }^{7}$, Anton Vonk Noordegraaf ${ }^{8}$, Pavel Jansa ${ }^{9}$, Michele D'Alto ${ }^{10}$, Milan Luknar ${ }^{11}$, Senka Milutinov $\| l i c^{12}$, Catharina Belge ${ }^{1,2}$, Olivier Sitbon ${ }^{3,4,5}$, Abílio Reis $^{13}$, Stephan Rosenkranz ${ }^{14}$, Joanna Pepke-Zaba ${ }^{15}$, Marc Humbert ${ }^{3,4,5}$ and Marion Delcroix ${ }^{1,2}$

\begin{abstract}
Background: During the COVID-19 pandemic, most of the health care systems suspended their non-urgent activities. This included the cancellation of consultations for patients with rare diseases, such as severe pulmonary hypertension $(\mathrm{PH})$, resulting in potential medication shortage and loss of follow-up. Thus, the aim of the study was to evaluate $\mathrm{PH}$ patient health status evolution, access to health care and mental health experience during the early phase of the pandemic.
\end{abstract}

Methods: We conducted an online patient survey, available in 16 languages, between 22/05/2020 and 28/06/2020. The survey included questions corresponding to demographic, COVID-19 and PH related information.

Results: 1073 patients (or relatives, 27\%) from 52 countries all over the world participated in the survey. Seventyseven percent (77\%) of responders reported a diagnosis of pulmonary arterial hypertension and $15 \%$ of chronic thromboembolic PH. The COVID-19 related events were few: only $1 \%$ of all responders reported a diagnosis of COVID-19. However, $8 \%$ of patients reported health deterioration possibly related to $\mathrm{PH}$, and $4 \%$ hospitalization for $\mathrm{PH}$. Besides, $11 \%$ of the patients reported difficulties to access their PH expert centre, and 3\% interruption of treatment due to shortage of medication. Anxiety or depression was reported by $67 \%$ of the participants.

Conclusion: Although COVID-19 incidence in PH patients was low, $\mathrm{PH}$ related problems occurred frequently as the pandemic progressed, including difficulties to have access to specialized care. The importance of primary health care was emphasized. Further studies are needed to evaluate the long-term consequences of COVID-related PH care disruption.

Keywords: Pulmonary hypertension, COVID-19, Patient survey, Pulmonary arterial hypertension, Chronic thromboembolic pulmonary hypertension

*Correspondence: Laurent.Godinas@uzleuven.be

${ }^{1}$ Department of Respiratory Diseases, University Hospitals Leuven, Leuven, Belgium

Full list of author information is available at the end of the article

\section{Introduction}

SARS-CoV-2 (severe acute respiratory syndrome coronavirus 2) emerged in China at the end of 2019 causing coronavirus disease 2019 (COVID-19). The outbreak rapidly spread around the world and on the 11th of original author(s) and the source, provide a link to the Creative Commons licence, and indicate if changes were made. The images or other third party material in this article are included in the article's Creative Commons licence, unless indicated otherwise in a credit line to the material. If material is not included in the article's Creative Commons licence and your intended use is not permitted by statutory regulation or exceeds the permitted use, you will need to obtain permission directly from the copyright holder. To view a copy of this licence, visit http://creativecommons.org/licenses/by/4.0/. The Creative Commons Public Domain Dedication waiver (http://creativeco mmons.org/publicdomain/zero/1.0/) applies to the data made available in this article, unless otherwise stated in a credit line to the data. 
March 2020, the World Health Organization declared that COVID-19 could be characterized as a pandemic. COVID-19 reached Europe in February 2020 resulting in a strict lockdown in most European countries between March and June 2020. During these three months, the healthcare systems encountered difficulties to ensure non-urgent care due to COVID-19 patient overload. A substantial part of outpatient consultations for patients with chronic or rare diseases were cancelled, with potential repercussions on their health status. In the meantime, these patients were considered to be at risk for severe forms of COVID-19 due to their underlying condition, especially in the case of patients with cardio-pulmonary diseases.

Pulmonary arterial hypertension (PAH) and other severe forms of pulmonary hypertension $(\mathrm{PH})$ such as chronic thromboembolic pulmonary hypertension (CTEPH), are rare diseases characterized by an elevated mean pulmonary arterial pressure above $20 \mathrm{mmHg}$, normal pulmonary artery wedge pressure, and elevated pulmonary vascular resistance above 3 Wood Units, due to progressive precapillary pulmonary artery remodelling $[1,2]$. They require highly specialized care in expert centers and treatment with PAH oral drugs, sometimes combined with inhaled, continuous intravenous or subcutaneous agents [3]. CTEPH patients could also benefit from surgical or interventional treatments. These complex treatments require frequent monitoring by specialized physicians and nurses. Furthermore, most of these drugs are expensive and not easily accessible due to health system restrictions.

$\mathrm{PH}$ patients were subjected to the same rules as other patients during the COVID-19 pandemic, with no prioritized care despite their rare and severe condition. Most of the $\mathrm{PH}$ centres, mainly run by cardiologists or respiratory physicians, suddenly stopped their activities considered non-urgent in order to focus on COVID-19 patient care, generally in response to directives from the local/national authorities. The difficulties to access specialized health care and specific drugs suggest that the interruption of care could have major repercussions on the health status of $\mathrm{PH}$ patients [4]. To get a rapid picture of the situation and problems encountered, a consortium composed of $\mathrm{PH}$ patient associations and scientific societies was created. The European Pulmonary Hypertension Association (PHA Europe), the European Reference Network for rare lung diseases (ERN-LUNG), the European Respiratory Society (ERS) Assembly 13 on Pulmonary Vascular Diseases, the ERS Clinical Research Collaboration PHAROS, the European Lung Foundation (ELF) and the European Society of Cardiology (ESC) Working Group on Pulmonary Circulation \& Right Ventricular Function decided to join forces to launch the PH-CARE-COVID survey, an international patient survey available in 16 languages, designed to collect information on PH patients' lived experience and to understand how $\mathrm{PH}$ care was provided during the pandemic-related lockdown.

\section{Methods}

\section{Survey design and dissemination}

An online survey of 34 questions was created regarding: (1) the demographics and disease related information; (2) the COVID experience of PH patients; and (3) the PH disease management during the COVID-19 pandemic. The original English version of the questionnaire is available in the Additional file 1.

The survey was translated from English into 15 languages (Bulgarian, Czech, Dutch, French, German, Hebrew, Italian, Latvian, Lithuanian, Portuguese, Serbian, Slovak, Slovenian, Spanish, Ukrainian). The translations were made by experienced native speakers from national patient associations and validated by a local $\mathrm{PH}$ specialist physician. The questionnaire was created using the "Survey Monkey" tool and made accessible on the PHA Europe website (https://www.phaeurope.org/ get-involved/advocacy-policy-work/covid-19-questionna ire/) and on the ERN-LUNG website (https://ern-lung. eu/portfolio-items/phcare-covid-survey/). The survey was disseminated by the European PH umbrella association, national $\mathrm{PH}$ patient associations and by $\mathrm{PH}$ centres through their websites, social networks and other suitable media. In addition, the ERS Assembly 13 on Pulmonary Vascular Diseases and the ESC Working Group on Pulmonary Circulation \& Right Ventricular Function specifically informed their affiliated $\mathrm{PH}$ physicians. An information folder concerning the survey was created that could be distributed to patients by the $\mathrm{PH}$ centres.

The survey was anonymous, however patients had the possibility to give an email address to receive further information, feedback of the study or other studies concerning the COVID-19 pandemic. There were no exclusion criteria concerning the type of PH (group 1 to 5 ). For some questions, more than one answer was possible.

\section{Income level determination}

Income level per country was based on the Gross National Income (GNI) per capita calculated using the World Bank Atlas Method and the data available on the website of Word Bank, data provided in US dollar per year [5]. Low-income economies are defined as those with a GNI per capita of $\$ 1,035$ or less in 2019; middle-income economies are those with a GNI per capita between $\$ 1,036$ and $\$ 12,535$; high-income economies are those with a GNI per capita of $\$ 12,536$ or more). 


\section{Data collection and analysis}

The survey was accessible between $22 / 05 / 2020$ and $28 / 06 / 2020$. The results were extracted from the "Survey Monkey" tool on an Excel sheet and were analysed using GraphPad Prism (v. 8). Google Translate was used to analyse open answers from participants when necessary.

\section{Results}

\section{Patient characteristics}

A total of 1073 individuals answered the survey. 73\% were patients and $27 \%$ relatives of patients. They came from 52 countries (Table 1), with the largest number of participants in Belgium $(n=144,13.4 \%)$, France $(n=125$, $11.6 \%)$, the Netherlands $(\mathrm{n}=116,10.8 \%)$, Chile $(\mathrm{n}=90$, $8.4 \%)$, and Spain $(\mathrm{n}=78,7.3 \%)$. Demographic data are presented in Table 2. Most of the cohort were adult (96\%) and $4 \%$ were paediatric patients (Fig. 1). The majority reported to have idiopathic PAH (39\%), followed by congenital heart disease associated PAH (19\%) and by CTEPH (15\%). In total, 92\% of the patients reported a diagnostic of PAH or CTEPH. Some patients could not provide an accurate diagnosis $(6 \%)$ and $1 \%$ gave answers other than PH group 1 and 4. Most of the patients (87\%) received oral therapy and $21 \%$ received parenteral therapy. The questionnaire did not allow to differentiate monotherapy from dual or triple combination therapy. Eleven percent of the patients denied receiving specific therapies, mostly corresponding to operated CTEPH patients, patients treated with calcium channel blockers, patients with ongoing diagnosis, and patients with $\mathrm{PH}$ types other than group 1 or 4 . The median follow up time in $\mathrm{PH}$ specialized centres was 4.5 years (IQ 2.0-10.0).

\section{COVID-19 experience of $\mathrm{PH}$ patients}

This part of the questionnaire aimed to understand whether PH patients experienced any COVID-19 related events (appearance of symptoms, testing, hospitalization) and their primary source of contact during this experience. During the early phase of the COVID-19 pandemic, $47 \%$ of the patients had no new symptom or aggravation of previously known symptoms (Fig. 2). The majority of the symptoms reported by patients were unspecific but compatible with viral diseases or PH (Fig. 2). Three percent of the patients reported a loss of smell or taste. 815 (76\%) patients judged their physical condition as stable, 155 (14\%) felt a deterioration and 40 (4\%) an improvement, while 63 (6\%) did not answer the question (Fig. 3a). In the 155 patients who experienced a deterioration, 54\% attributed it to $\mathrm{PH}$ (8\% of total participants), $50 \%$ to a lack of activity due to lockdown ( $7 \%$ of total), $41 \%$ to anxiety and depression ( $6 \%$ of total), $11 \%$ ( $2 \%$ of total) to the lack of medications and only $10 \%$ directly to COVID (1\% of total) (Fig. 3b).
Table 1 Distribution of the participants per country

\begin{tabular}{|c|c|c|}
\hline Name of country & $\begin{array}{l}\text { Total answers per } \\
\text { country }\end{array}$ & $\begin{array}{l}\% \text { of the total } \\
\text { answers of the } \\
\text { survey }\end{array}$ \\
\hline Belgium & 144 & 13.4 \\
\hline France & 125 & 11.6 \\
\hline The Netherlands & 116 & 10.8 \\
\hline Chile & 90 & 8.4 \\
\hline Spain & 78 & 7.3 \\
\hline Ukraine & 74 & 7.0 \\
\hline Portugal & 66 & 6.2 \\
\hline Italy & 47 & 4.4 \\
\hline Austria & 37 & 3.4 \\
\hline Germany & 29 & 2.7 \\
\hline Serbia & 24 & 2.2 \\
\hline Latvia & 23 & 2.1 \\
\hline Slovakia & 21 & 2.0 \\
\hline Slovenia & 18 & 1.7 \\
\hline Canada & 17 & 1.6 \\
\hline India & 17 & 1.6 \\
\hline United Kingdom & 15 & 1.4 \\
\hline Brazil & 13 & 1.2 \\
\hline Colombia & 12 & 1.1 \\
\hline Czechia & 12 & 1.1 \\
\hline USA & 9 & 0.8 \\
\hline Bosnia & 9 & 0.8 \\
\hline Croatia & 9 & 0.8 \\
\hline Lithuania & 8 & 0.7 \\
\hline Argentina & 7 & 0.7 \\
\hline Peru & 7 & 0.7 \\
\hline Uruguay & 6 & 0.6 \\
\hline Australia & 4 & 0.4 \\
\hline Bulgaria & 4 & 0.4 \\
\hline Finland & 3 & 0.3 \\
\hline Dominican Republic & 3 & 0.3 \\
\hline Norway & 2 & 0.2 \\
\hline Poland & 2 & 0.2 \\
\hline Sweden & 2 & 0.2 \\
\hline Honduras & 2 & 0.2 \\
\hline Greece & 2 & 0.2 \\
\hline New Zealand & 1 & $<0.1$ \\
\hline Mexico & 1 & $<0.1$ \\
\hline Montenegro & 1 & $<0.1$ \\
\hline El Salvador & 1 & $<0.1$ \\
\hline Costa Rica & 1 & $<0.1$ \\
\hline Ecuador & 1 & $<0.1$ \\
\hline Venezuela & 1 & $<0.1$ \\
\hline Switzerland & 1 & $<0.1$ \\
\hline Algeria & 1 & $<0.1$ \\
\hline Morocco & 1 & $<0.1$ \\
\hline Malaysia & 1 & $<0.1$ \\
\hline South Africa & 1 & $<0.1$ \\
\hline
\end{tabular}


Table 1 (continued)

\begin{tabular}{lll}
\hline Name of country & $\begin{array}{l}\text { Total answers per } \\
\text { country }\end{array}$ & $\begin{array}{l}\% \text { of the total } \\
\text { answers of the } \\
\text { survey }\end{array}$ \\
\hline Russia & 1 & $<0.1$ \\
Hungary & 1 & $<0.1$ \\
Lebanon & 1 & $<0.1$ \\
Tajikistan & 1 & $<0.1$ \\
\hline
\end{tabular}

Table 2 Demographics, $\mathrm{PH}$ etiology and $\mathrm{PH}$ specific therapies. $P A H$ pulmonary arterial hypertension, $P H$ pulmonary hypertension

\begin{tabular}{llr}
\hline & $\mathbf{N}=\mathbf{1 0 7 3}$ & $\%$ \\
\hline Gender & & \\
Female & 839 & 78.2 \\
Male & 228 & 21.2 \\
No answer & 6 & 0.6 \\
PH etiology & & \\
Idiopathic PAH & 416 & 38.8 \\
Heritable/genetic PAH & 80 & 7.5 \\
Drug related PAH & 15 & 1.4 \\
Liver disease related PAH & 16 & 1.5 \\
Connective tissue disease related PAH & 93 & 8.7 \\
Congenital heart malformation related PAH & 208 & 19.4 \\
Chronic thromboembolic PH & 161 & 15.0 \\
Other & 13 & 1.2 \\
I do not know/l am not sure/Do not want to answer & 71 & 6.6 \\
Treatments & & \\
Oral & 934 & 87.0 \\
Intravenous & 76 & 7.1 \\
Subcutaneous & 77 & 7.2 \\
Inhaled & 72 & 6.7 \\
Study medication & 18 & 1.7 \\
No specific PH treatment reported & 115 & 10.7 \\
\hline
\end{tabular}

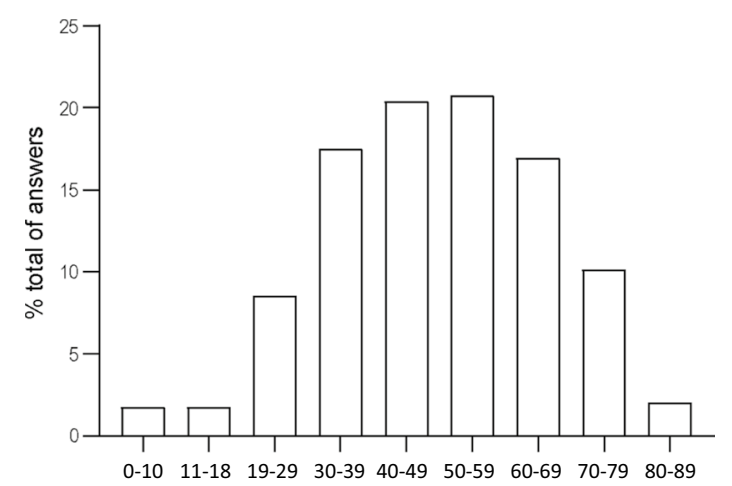

Fig. 1 Age distribution of the patients

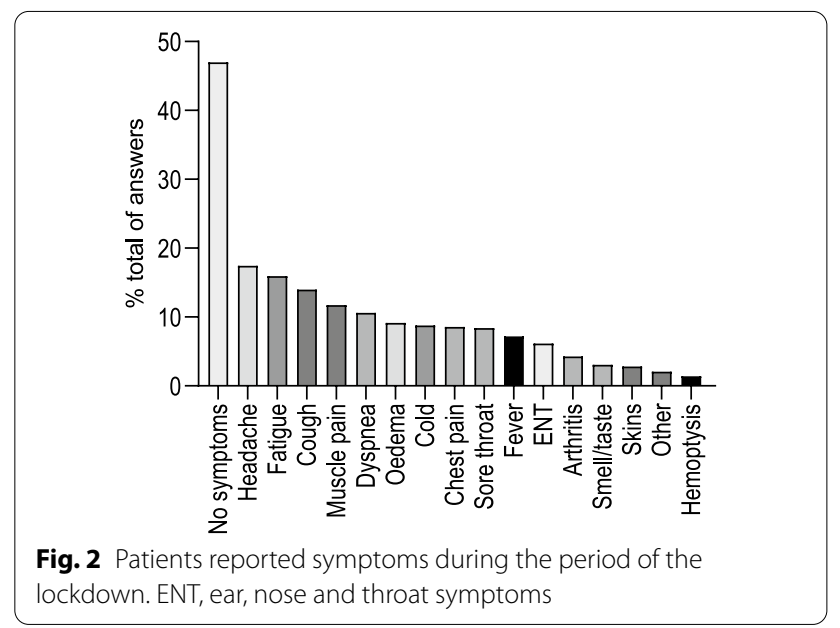

Most of the patients $(756,70 \%)$ reported not to have been in contact with health professionals for problems or questions related to COVID, while 263 patients (25\%) reportedly contacted health professionals for COVID related reasons. 54 patients $(5 \%)$ did not answer this question. Out of the 263 patients who reported contact, $122(46 \%)$ reported a contact with their general practitioner (GP), 128 (49\%) with their treating PH physician, 70 (27\%) with their specialized PH nurses, 45 (17\%) with a cardiologist or a pneumologist other than their PH physician, 21 (8\%) with emergency/intensive care unit (ICU) physicians and $25(10 \%)$ with other health professionals (mainly specialists or nurses outside of the specialist centres) (Fig. 4a).

918 (86\%) patients were not tested for COVID-19, while $104(10 \%)$ were. Out of the $10 \%$ who were tested, $90 \%$ of the tests were negative and only $9 \%$ positive, corresponding to 9 patients who tested positive for COVID-19. 13 patients (1\%) reported hospitalization for COVID-19, of which with 4 patients were hospitalized in their own $\mathrm{PH}$ centre and 7 in centres other than their respective $\mathrm{PH}$ centres. Only 2 patients reported hospitalization in intensive care units. The median length of stay in hospital was 6 days (min: 2, max: 43).

\section{Impact of COVID-19 on PH care}

This part of the questionnaire aimed to understand the possible impact of COVID-19 on $\mathrm{PH}$ care continuity and health status evolution. 475 (44\%) participants were in contact with health professionals concerning questions or problems related to $\mathrm{PH}, 535$ (50\%) were not and 63 (6\%) did not answer. From the $44 \%$ of patients who reported contact, 150 (32\%) reported a contact with their GP, 307 (65\%) with their treating PH physician, 129 (27\%) with their specialized nurse team, 80 (17\%) with a cardiologist or a pneumologist other than their $\mathrm{PH}$ 


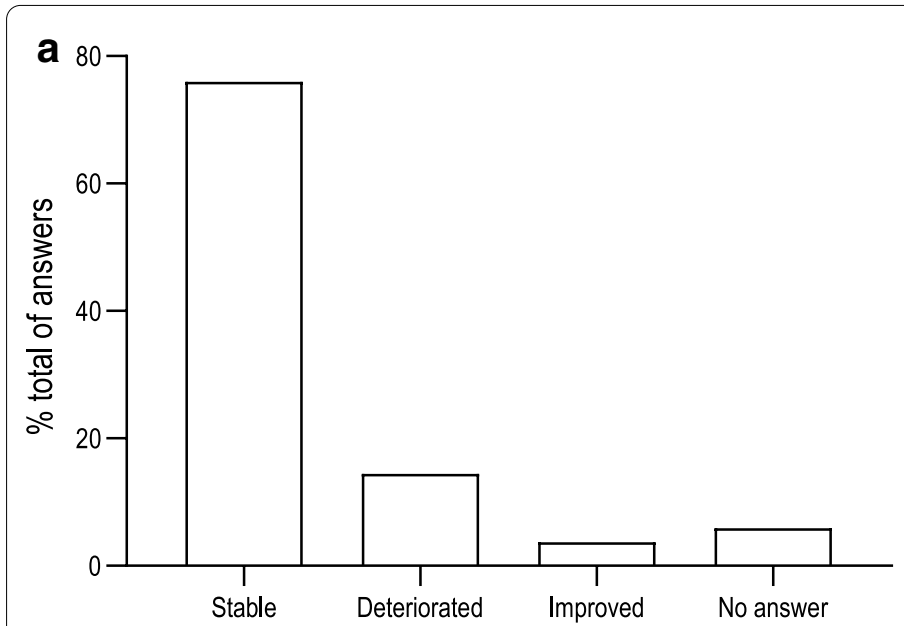

b

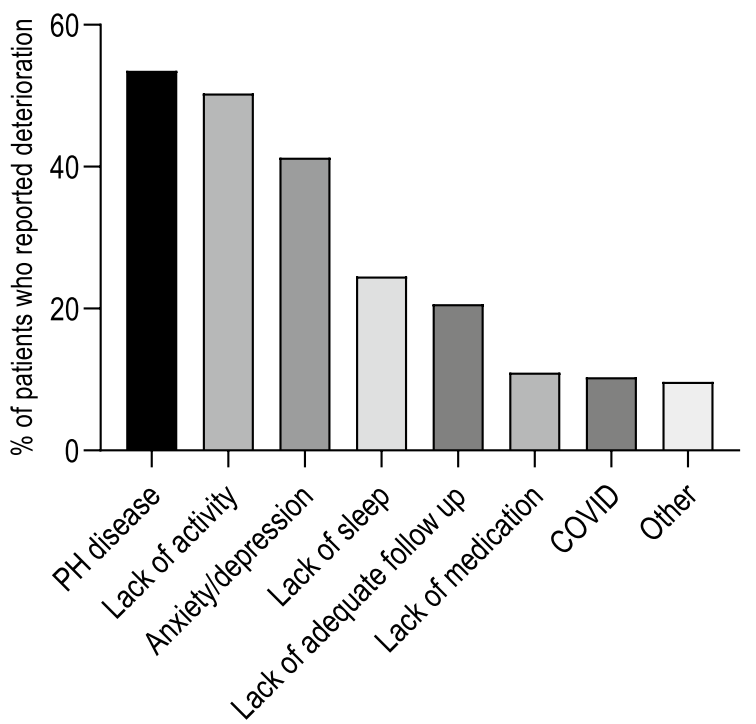

Fig. 3 a Evolution of self-reported health status during the lockdown. b Self-reported causes of deterioration for patients who reported a deterioration of their health status. PH pulmonary hypertension
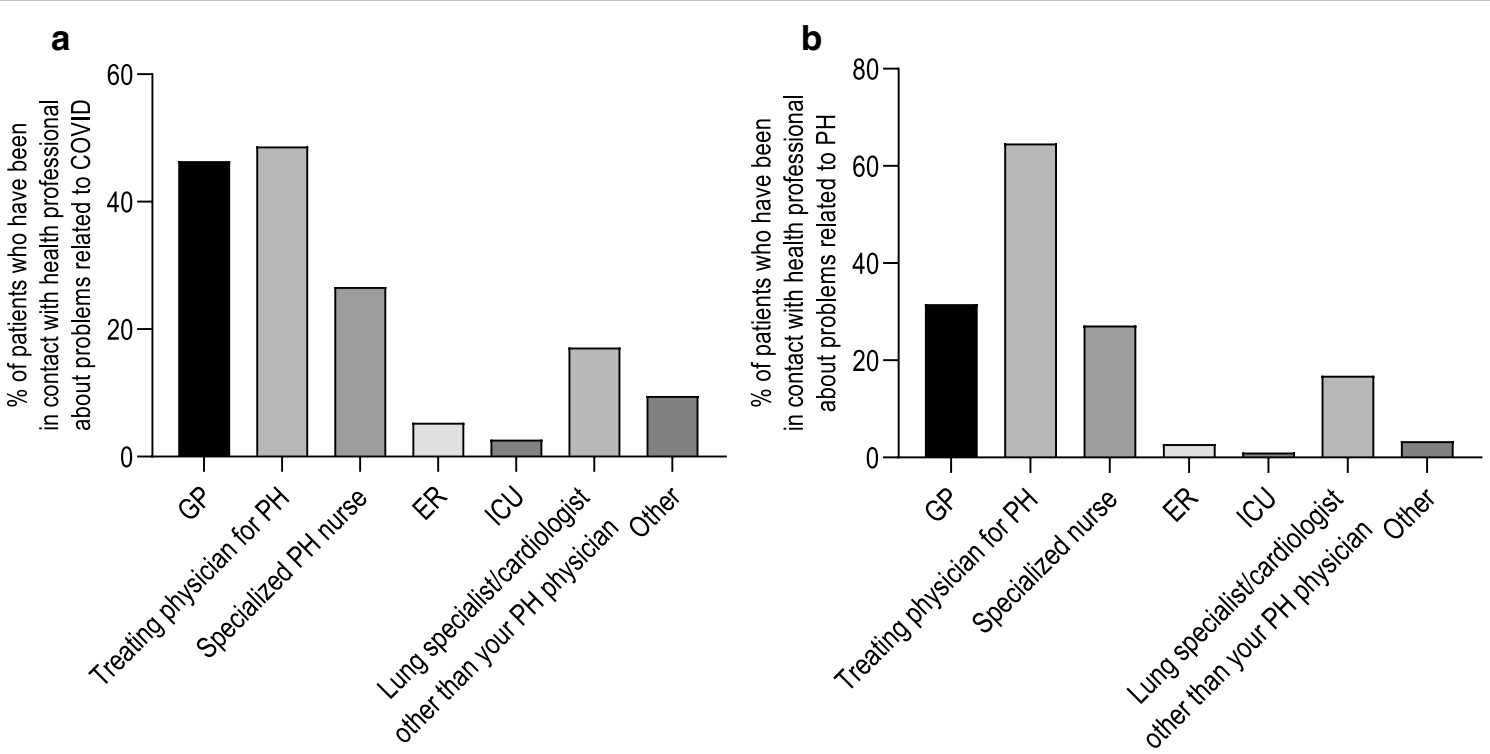

Fig. 4 a Patients self-reported contacts with health professionals concerning COVID-related issues. b Patients self-reported contacts with health professionals concerning PH-related issues. ER emergency room, GP general practitioner, ICU intensive care unit, PH pulmonary hypertension

physician, 18 (4\%) with emergency/ICU physicians and 16 (3\%) with other health professionals (mainly specialists or nurses outside of the specialist centres) (Fig. $4 \mathrm{~b}$ ). Among patients who did not report any contact, no consultations were planned for 317 of them (59\%), 41 (8\%) were afraid to disturb their physicians, 111 (21\%) were afraid to go to a public place/hospital, 73 (14\%) did not consider their problem to be important and 57 (11\%) for other reasons. During the early phase of the COVID-19 pandemic, 959 (89\%) patients reported no $\mathrm{PH}$-related hospitalization, $43(4 \%)$ were hospitalized due to their $\mathrm{PH}$ condition, and $71(6 \%)$ did not answer. Among the 43 who were hospitalized, 30 were hospitalized in their own $\mathrm{PH}$ centre (emergency room $=5$, general ward $=21$, 
ICU $=3$ ) and 11 reported to have been hospitalized in another centre (emergency room $=4$, general ward $=4$, $\mathrm{ICU}=3)$. The median length of hospitalization was 7 days (min: 1, max: 83). Survey participants were also asked if they had trouble to reach health professionals or to have access to healthcare services during the early phase of the COVID-19 pandemic. 117 (11\%) reported difficulties to join their PH treating team, 101 (9\%) to join health professionals other than their PH team, 175 (16\%) to obtain adequate information related to the repercussion of COVID-19 on PH and 172 (16\%) to receive their $\mathrm{PH}$ specific medications. $\mathrm{PH}$ patients were also asked whether they experienced cancellation of their appointments/medical check-ups and how the rescheduling was managed. 448 (42\%) experienced no cancellation while 530 (49\%) did. Among those who did, 342 (32\%) reported cancellation of consultation with their $\mathrm{PH}$ team and 377 (35\%) reported cancellation of exams related to $\mathrm{PH}$. For those who experienced cancellation, 338 (64\%) reported to have had their appointments cancelled by their $\mathrm{PH}$ centre, 87 (16\%) decided to cancel by themselves and 108 (20\%) decided in concertation with their PH physician; 138 patients ( $13 \%$ of the total of answering patients) reported not having received any new appointment or other instructions concerning rescheduling.

$130(12 \%)$ patients reported to have reached their $\mathrm{PH}$ team by face-to-face contact, $455(42 \%)$ by phone call, 83 (8\%) by video call, 280 (26\%) via email and $65(6 \%)$ only via post.

Specific questions concerning the continuity of treatments were also asked: $870(81 \%)$ patients reported no change in their treatment, $27(3 \%)$ reported a treatment interruption due to shortage of medication, 6 (1\%) stopped for reasons other than shortage and 41 (4\%) reported a modification of their treatment. Among the patients who stopped their treatment due to shortage, the duration was less than one week for $6(22 \%)$, between 1 and 4 weeks for 10 (37\%), and more than 4 weeks for 11 (41\%) patients. 7 patients reported stopping oral treatment and 2 stopped intravenous treatment. 4 patients reported the information to their $\mathrm{PH}$ centre and 5 to their GP. Out of the 27 patients who reported interruption of medication due to shortage, $37 \%$ were patients from high-income countries and 63\% from middle-income countries.

Concerning how they felt regarding their health status as $\mathrm{PH}$ patients during the pandemic, 508 (47\%) patients experienced anxiety, 59 (5\%) were upset, 211 (20\%) reported sadness or depression and $95(9 \%)$ felt abandoned (Fig. 5). Regarding the medical care that PH patients received during the early phase of the COVID19 pandemic, 556 (52\%) were satisfied or very satisfied,

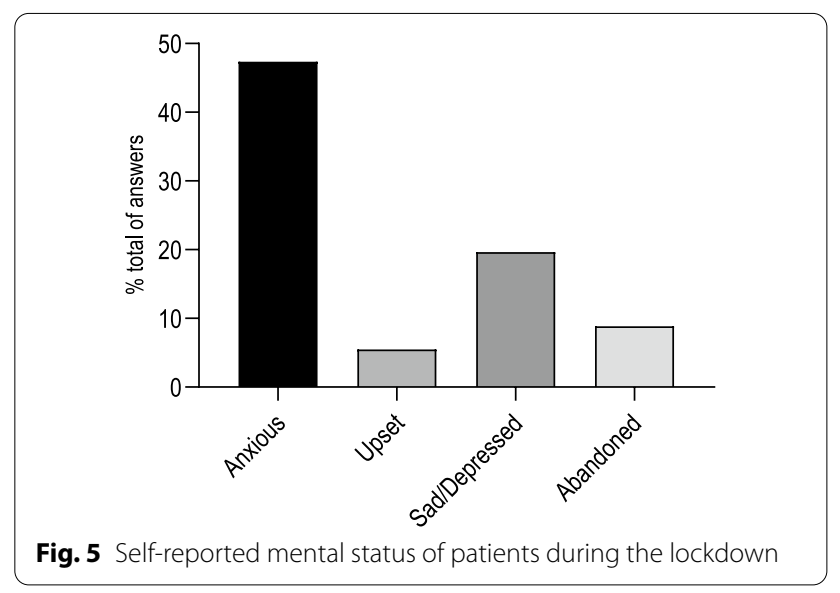

$200(19 \%)$ were neutral and 59 (5\%) were unsatisfied or very unsatisfied.

606 (56\%) patients reported to have searched for specific information concerning the repercussions of COVID-19 on PH health status. For these patients, the main sources of information were the internet $(n=433$, $71 \%)$, patient associations $(n=208,34 \%)$, their $\mathrm{PH}$ treating team $(\mathrm{n}=178,29 \%), \mathrm{GP}(\mathrm{n}=104,17 \%)$ and other health professionals $(n=53,9 \%)$.

Finally, 55\% of the participants considered their $\mathrm{PH}$ centres to be well prepared to face the pandemic and 73\% thought that $\mathrm{PH}$ patient associations could have a crucial role to play in such events in the future.

\section{Discussion}

In this patient survey representing the experience of 1073 $\mathrm{PH}$ patients and their caregivers, we showed that (1) about $1 \%$ of the $\mathrm{PH}$ patients reported testing positive for COVID-19, while reporting of health status deterioration was tenfold higher and mainly related to $\mathrm{PH}$, deconditioning and mood disorders; (2) reported hospitalizations were 4 times more frequent for PH than for COVID-19; (3) $50 \%$ of the patients stayed in contact remotely with their $\mathrm{PH}$ team, mainly via phone calls and e-mails; (4) continuity of care was not possible for a significant part of the patients regarding contacts with their $\mathrm{PH}$ team, absence of scheduled follow-up and shortage of medication; (5) primary health care system was frequently consulted regarding COVID-19 related problems; (6) finally, the internet and patient associations were the most frequently consulted sources by $\mathrm{PH}$ patients for information related to COVID-19.

Since the early days of the pandemic, cardiovascular and respiratory conditions have been associated with poor outcome in COVID-19 [6]. Moreover, the rapidly recognized nature of pulmonary vasculopathy [7] and 
high rate of venous thromboembolic events in COVID19 patients [8] pointed towards increased risks of severity in $\mathrm{PH}$ patients [9]. In our series, less than 10 patients (1\%) were diagnosed with COVID-19. A previous study by Lee et al. reported a lower incidence, with a COVID-19 rate of 2.1 per $1000 \mathrm{PH}$ patients in the US, similar to the incidence in US global population, but with a high rate of mortality [10]. Belge et al. also reported a high mortality rate of 19\% in PH patients with COVID-19 from a survey of $\mathrm{PH}$ centres [11]. In the current survey, incidence was higher but severity seemed lower. The difference in incidence could be explained by temporal and demographic considerations with higher incidence rate of COVID-19 infection in Europe than in the US in the early phase of the pandemic [12]. The lower severity of COVID-19 could be due to under-representation of severe COVID19 cases, due to death or insufficient recovery at the time of the survey or older age. However, the incidence of $1 \%$ seems plausible. Indeed, in regions with high COVID-19 incidence, serological studies in the early pandemic phase have shown seroprevalence up to $23 \%$ in Lombardy [13], $7.6 \%$ in Korea [14], and 6.2\% in Philadelphia, USA [15]. It is probable that most of the patients with cardio-pulmonary comorbidities have been very cautious regarding SARS-CoV-2 infection, strictly following social distancing and isolation recommendations because of awareness of risk of developing severe disease [16]. Moreover, $3 \%$ of the patients reported loss of smell, which could be related to less symptomatic SARS-CoV-2 infection [17]. Further serological studies and large-scale health systems data analysis are required to confirm the exact incidence of COVID-19 in PH populations. Concerning COVID19-related hospitalization, we found a median duration of stay in hospital of 6 days, which seems relatively similar to a recent $\mathrm{PH}$ centre survey which reported 3 days [11]. This duration is compatible with a majority of moderate COVID-19 cases in PH patients but could hide quite large disparities, mainly for more severe patients requiring ICU hospitalizations.

The second major concern for $\mathrm{PH}$ patients was the reorganization of care during the lockdown which had considerable impact on other diseases [18], and especially in cardiovascular disease [19], with low access to healthcare system, prioritization of access to specific patients, lack of material or shortage of medications [20]. Worse outcomes due to delay in care has also been shown for acute cardiovascular problems [21]. However, there were some disparities between countries depending on country income $[22,24]$. Our current survey provided a unique opportunity to assess this problem in $\mathrm{PH}$ patients. We found that a low but significant number of $\mathrm{PH}$ patients encountered difficulties to have access to the healthcare system during the lockdown, with difficulties to reach $\mathrm{PH}$ specialized physicians or to continue therapy due to shortage. Interestingly, two thirds of the patients who stopped their medication were patients from middle-income countries as opposed to one third from highincome countries, spreading light on healthcare system disparities during the lockdown [25]. In addition, some patients' appointments were cancelled without new appointments or rescheduling instructions. This lack of continuity of care during the pandemic should be a specific issue to address in $\mathrm{PH}$ centers and specific policies should be implemented in prevision of new episodes of the pandemic [26].

An important proportion of the patients were able to maintain contact with their $\mathrm{PH}$ specialized physicians during the early phase of the pandemic, mainly via phone call and e-mail, allowing some health status monitoring. Other medical disciplines have shown different ways to stay in touch with patients to be successful $[27,28]$. These solutions should be considered and telemedicine plans prepared for the future [20]. Interestingly, concerning COVID-19 related problems, the $\mathrm{PH}$ patients turned to their GP as frequently as to their PH physicians, reinforcing the role of the primary care system during the pandemic [29]. Therefore, effective communication between $\mathrm{PH}$ expert centres and primary health care system should occur regarding pandemic-related specific recommendations for patients with rare diseases. Moreover, patients reported the internet and $\mathrm{PH}$ patient associations as important sources of information. These specific means of communication should be recognized and largely used in case of a new pandemic.

Fourteen percent of the patients noted a deterioration of their health status during the early phase of the pandemic. Although probably multifactorial, this deterioration may be related to progression of the underlying pulmonary vascular disease due to a potential delay in adequate management [21]. The strategy of early identification of these patients in the resumption of activity and in case of further pandemics, should be implemented [30]. The role of deconditioning and mood disorders due to confinement should require attention. Rehabilitation program and remote psychological support should be proposed to patients who need it.

Although COVID-19 occupied centre stage during the early phase of the pandemic, the $\mathrm{PH}$ patients seem to have been hit 4 times more by $\mathrm{PH}$ related issues than by COVID-19. It is, to our knowledge, the first broad evaluation of problems encountered by $\mathrm{PH}$ patients and the first time that we can quantify and compare the proportion of $\mathrm{PH}$ related problems with COVID-19 related problems. Our data clearly show the importance of maintaining a continuity of care for PH patients and they clearly suggest that specific recommendations should be made to 
allow maintenance of good quality care in the specific context of a pandemic and lockdown conditions.

Our approach has some limitations. Firstly, it is a patient survey and no direct control exists on the data provided by patients, especially no medical control concerning the reporting of the clinical deterioration by the patients. However, the large number of answers is quite reassuring, ironing out the potential mistakes or inaccuracies in patients' answers. Secondly, although we received a high number of answers, this survey was conducted around the world, resulting in quite a low number of answers from some countries, precluding in depth analysis and comparisons per country. However, taking into account the disparity in health systems, incomes and the timing of the pandemic, reporting on the global experience of the $\mathrm{PH}$ patients seems relevant and gives a unique overview of the worldwide impact of the pandemic on the continuity of care in PH. Finally, patients experiencing fatal or very severe outcomes after SARSCoV-2 infection or $\mathrm{PH}$ clinical deterioration will not participate in this kind of survey. This precludes the collection of data in this specific subgroup highly impacted by the pandemic, constituting a bias that has to be taken into account.

In conclusion, $\mathrm{PH}$-related problems were encountered more frequently than COVID-19-related problems during the early phase of the pandemic. Further studies are needed to evaluate the long-term consequences of COVID-19-related PH care disruption. Information on the impact of COVID-19 on various rare lung conditions must be made available to patients and caregivers, while remaining vigilant to prevent the spread of misinformation. The importance of primary healthcare even in the case of specialized rare conditions should not be undermined. This data could be of interest for further planning of strategies and organization of $\mathrm{PH}$ centres to ensure continuity of care and adequate communications with patients, caregivers, and health care providers, including primary care physicians.

\section{Supplementary Information}

The online version contains supplementary material available at https://doi. org/10.1186/s13023-021-01752-1.

Additional file 1. English questionnaire of the survey.

Additional File 2. Complete results of the answers to the questionnaire

\section{Acknowledgements}

This survey is a common initiative of the patient association European Pulmonary Hypertension Association (PHA Europe), the European Reference Network for rare lung diseases (ERN-LUNG), the European Respiratory Society
(ERS) Assembly 13 on Pulmonary Vascular Diseases and the ERS Clinical Research Collaboration PHAROS, the European Lung Foundation (ELF) and the European Society of Cardiology (ESC) Working Group on Pulmonary Circulation \& Right Ventricular Function. We thank the translators and the PH specialists who have translated and reviewed the accuracy of the questionnaire in their native languages: Roman Balmush, Louise Bouman, Teresa Carvalho, Dominika Carvanova, Lyubomir Dimitrov, Dora Erdelyi, Mélanie GallantDewavrin, Rima Gruodiene, Kamil Hamidullah, Ulla Hodgson, Sabina Hodzic, Elena Jureviciene, Kristof Karlocai, Nina Kobler, Sonja Koski, Peter Makovnik, Ioan Mircea Coman, Danijela Pesic, leva Plume, Leonardo Radicchi, Laura Ranz, Arsen Ristic, Barbara Salobir, Santa Strazdina, Sena Sert, Monika Tschida, Vjara Vragova, Iryna Zhuchenko, Iryna Zhyvylo.

\section{Authors' contributions}

Conception: MD, LG, RQ, CB, IK, GM, MH; design of the survey: MD, LG, IK, GM, JPZ; acquisition of the data: LG, IK, GM, CB, PES, AVN, PJ, MDA, ML, SMI, OS, AR, $S R$, JPZ; interpretation of data: LG, MD, MH, IK, GM; draft of the manuscript and revision: $\mathrm{LG}, \mathrm{IK}, \mathrm{GM}, \mathrm{MD}, \mathrm{MH}, \mathrm{AVN}, \mathrm{PJ}, \mathrm{ML}, \mathrm{CB}, \mathrm{RQ}$. All authors read and approved the final manuscript.

Funding

This survey received no funding.

Availability of data and materials

All the results of the survey are available in supplementary materials (Additional file 2)

Ethics approval and consent to participate

Not applicable.

Consent for publication

Not applicable.

\section{Competing interests}

The authors declare that they have no competing interests.

Informed consent

All the patients gave their informed consent at the early stage of the survey.

\section{Author details}

${ }^{1}$ Department of Respiratory Diseases, University Hospitals Leuven, Leuven, Belgium. ${ }^{2}$ Laboratory of Respiratory Diseases and Thoracic Surgery (BREATHE), Department of Chronic Diseases and Metabolism (CHROMETA), KU Leuven - University of Leuven, Leuven, Belgium. ${ }^{3}$ Faculté de Médecine, Université Paris-Saclay, Le Kremlin Bicêtre, France. ${ }^{4}$ Assistance Publique Hôpitaux de Paris, Service de Pneumologie, Centre de Référence de L'Hypertension Pulmonaire, ERN-LUNG, Hôpital Bicêtre, Le Kremlin Bicêtre, France. ${ }^{5}$ Inserm UMR_S 999, Hôpital Marie Lannelongue, Le Plessis Robinson, France. ${ }^{6}$ European Pulmonary Hypertension Association, Vienna, Austria. ${ }^{7}$ Cardiology Department and Spanish Cardiovascular Research Network (CIBER-CV), Hospital Universitario, 12 de Octubre, Madrid, Spain. ${ }^{8}$ Departement of Pulmonary Medicine, Vrije Universiteit Amsterdam, Amsterdam UMC, De Boelelaan 1117, Amsterdam, Netherlands. ${ }^{9}$ Department of Medicine - Department of Cardiovascular Medicine, First Faculty of Medicine, Charles University and General University Hospital, Prague, Czech Republic. ${ }^{10}$ Department of Cardiology, Monaldi Hospital, Naples, Italy. ${ }^{11}$ National Cardiovascular Institute, Comenius University School of Medicine, Pod Krasnou Horkou 1, Bratislava, Slovakia. ${ }^{12}$ Institute for Pulmonary Diseases of Vojvodina, Sremska Kamenica, Serbia. ${ }^{13}$ Medicine Department, Pulmonary Vascular Diseases Unit, Centro Hospitalar Universitário Do Porto, Porto, Portugal. ${ }^{14}$ Department III of Internal Medicine and, Cologne Cardiovascular Research Center (CCRC), Cologne University Heart Center, Cologne, Germany. ${ }^{15}$ Pulmonary Vascular Diseases Unit, Royal Papworth Hospital, Cambridge, UK.

Received: 8 December 2020 Accepted: 16 February 2021

Published online: 01 May 2021 


\section{References}

1. Simonneau G, Montani D, Celermajer DS, Denton CP, Gatzoulis MA, Krowka M, et al. Haemodynamic definitions and updated clinical classification of pulmonary hypertension. Eur Respir J. 2019;53(1):1801913.

2. Humbert M, Guignabert C, Bonnet S, Dorfmüller P, Klinger JR, Nicolls MR, et al. Pathology and pathobiology of pulmonary hypertension: state of the art and research perspectives. Eur Respir J. 2019;53(1):1801887.

3. «2015 ESC/ERS Guidelines for the diagnosis and treatment of pulmonary hypertension. The Joint Task Force for the Diagnosis and Treatment of Pulmonary Hypertension of the European Society of Cardiology (ESC) and the European Respiratory Society (ERS).» Nazzareno Galiè, Marc Humbert, Jean-Luc Vachiery, Simon Gibbs, Irene Lang, Adam Torbicki, Gérald Simonneau, Andrew Peacock, Anton Vonk Noordegraaf, Maurice Beghetti, Ardeschir Ghofrani, Miguel Angel Gomez Sanchez, Georg Hansmann, Walter Klepetko, Patrizio Lancellotti, Marco Matucci, Theresa McDonagh, Luc A. Pierard, Pedro T. Trindade, Maurizio Zompatori and Marius Hoeper. Eur Respir J 2015; 46: 903-75. Eur Respir J. déc 2015;46(6):1855-6.

4. Bhatia RT, Gati S, Papadakis M, Sharma S. The impact of COVID-19 on the continuity of cardiovascular care. Eur Heart J. 2021;42(3):215-7.

5. GNI per capita, Atlas method [Internet]. World Bank Group; [cité 29 sept 2020]. Disponible sur: https://data.worldbank.org/indicator/NY.GNP.PCAP. CD

6. Gupta S, Hayek SS, Wang W, Chan L, Mathews KS, Melamed ML, et al. Factors Associated With Death in Critically III Patients With Coronavirus Disease 2019 in the US. JAMA Intern Med. 152020

7. Ackermann M, Verleden SE, Kuehnel M, Haverich A, Welte T, Laenger F, et al. Pulmonary vascular endothelialitis, thrombosis, and angiogenesis in Covid-19. N Engl J Med. 2020;383(2):120-8

8. Wichmann D, Sperhake J-P, Lütgehetmann M, Steurer S, Edler C, Heinemann A, et al. Autopsy findings and venous thromboembolism in patients with COVID-19. Ann Intern Med. 2020

9. Horn EM, Chakinala M, Oudiz R, JoseloffE, Rosenzweig EB. Could pulmonary arterial hypertension patients be at a lower risk from severe COVID19? Pulm Circ juin. 2020;10(2):2045894020922799.

10. Lee JD, Burger CD, Delossantos GB, Grinnan D, Ralph DD, Rayner SG, et al. A survey-based estimate of COVID-19 incidence and outcomes among patients with PAH or CTEPH and impact on the process of care. Ann Am Thorac Soc. 2020

11. Belge C, Quarck R, Godinas L, Montani D, Escribano-Subias P, Vachiéry J-L, et al. Covid-19 in pulmonary arterial hypertension and chronic thromboembolic pulmonary hypertension: a reference center survey. ERJ Open Res (in press)

12. Johns Hopkins Coronavirus Resource Center. In: Johns Hopkins University \& Medicine. Disponible sur: https://coronavirus.jhu.edu/

13. Percivalle E, Cambiè G, Cassaniti I, Nepita EV, Maserati R, Ferrari A, et al. Prevalence of SARS-CoV-2 specific neutralising antibodies in blood donors from the Lodi Red Zone in Lombardy, Italy, as at 06 April 2020. Euro Surveill Bull Eur Sur Mal Transm Eur Commun Dis Bull. 2020;25(24).

14. Song SK, Lee DH, Nam JH, Kim KT, Do JS, Kang DW, et al. IgG Seroprevalence of COVID-19 among individuals without a history of the coronavirus disease infection in Daegu, Korea. J Korean Med Sci. 2020;35(29):e269.

15. Flannery DD, Gouma S, Dhudasia MB, Mukhopadhyay S, Pfeifer MR, Woodford EC, et al. SARS-CoV-2 seroprevalence among parturient women in Philadelphia. Sci Immunol. 2020;5(49).
16. Alqahtani JS, Oyelade T, Aldhahir AM, Alghamdi SM, Almehmadi M, Alqahtani AS, et al. Prevalence, severity and mortality associated with COPD and smoking in patients with COVID-19: a rapid systematic review and meta-analysis. PLoS ONE. 2020;15(5):e0233147.

17. Moein ST, Hashemian SM, Mansourafshar B, Khorram-Tousi A, Tabarsi P, Doty RL. Smell dysfunction: a biomarker for COVID-19. Int Forum Allergy Rhinol. 2020;10(8):944-50.

18. Burki TK. Cancer guidelines during the COVID-19 pandemic. Lancet Oncol. 2020:21(5):629-30.

19. De Rosa S, Spaccarotella C, Basso C, Calabrò MP, Curcio A, Filardi PP, et al. Reduction of hospitalizations for myocardial infarction in Italy in the COVID-19 era. Eur Heart J. 2020:41(22):2083-8.

20. Mauro V, Lorenzo M, Paolo C, Sergio H. Treat all COVID 19-positive patients, but do not forget those negative with chronic diseases. Intern Emerg Med août. 2020;15(5):787-90

21. Mafham MM, Spata E, Goldacre R, Gair D, Curnow P, Bray M, et al. COVID19 pandemic and admission rates for and management of acute coronary syndromes in England. Lancet Lond Engl. 2020;396(10248):381-9.

22. Verma A, Rajput R, Verma S, Balania VKB, Jangra B. Impact of lockdown in COVID 19 on glycemic control in patients with type 1 Diabetes Mellitus. Diabetes Metab Syndr. 2020;14(5):1213-6.

23. Fernández E, Cortazar A, Bellido V. Impact of COVID-19 lockdown on glycemic control in patients with type 1 diabetes. Diabetes Res Clin Pract. 2020;166:108348.

24. Belkacemi Y, Grellier N, Ghith S, Debbi K, Coraggio G, Bounedjar A, et al. A review of the international early recommendations for departments organization and cancer management priorities during the global COVID-19 pandemic: applicability in low- and middle-income countries. Eur J Cancer Oxf Engl. 1990;2020(135):130-46.

25. Hong W-Z, Chan G-C, Chua H-R. Continuing chronic disease care during COVID-19 and beyond. J Am Med Dir Assoc juill. 2020;21(7):991-2.

26. Gebbia V, Piazza D, Valerio MR, Borsellino N, Firenze A. Patients with cancer and COVID-19: A WhatsApp Messenger-based survey of patients' queries, needs, fears, and actions taken. JCO Glob Oncol. 2020;6:722-9.

27. McElroy JA, Day TM, Becevic M. The influence of telehealth for better health across communities. Prev Chronic Dis. 2020;17:200254.

28. Krist AH, DeVoe JE, Cheng A, Ehrlich T, Jones SM. Redesigning primary care to address the COVID-19 pandemic in the midst of the pandemic. Ann Fam Med juill. 2020;18(4):349-54.

29. Tapper EB, Asrani SK. The COVID-19 pandemic will have a long-lasting impact on the quality of cirrhosis care. J Hepatol août. 2020;73(2):441-5.

30. Palmer K, Monaco A, Kivipelto M, Onder G, Maggi S, Michel J-P, et al. The potential long-term impact of the COVID-19 outbreak on patients with non-communicable diseases in Europe: consequences for healthy ageing. Aging Clin Exp Res juill. 2020;32(7):1189-94.

\section{Publisher's Note}

Springer Nature remains neutral with regard to jurisdictional claims in published maps and institutional affiliations.

Ready to submit your research? Choose BMC and benefit from

- fast, convenient online submission

- thorough peer review by experienced researchers in your field

- rapid publication on acceptance

- support for research data, including large and complex data types

- gold Open Access which fosters wider collaboration and increased citations

- maximum visibility for your research: over 100M website views per year

At BMC, research is always in progress.

Learn more biomedcentral.com/submissions 